\title{
Accountability in crises: Connecting evidence from humanitarian and social protection approaches to social assistance
}

\author{
Louisa Seferis and Paul Harvey
}

February 2022

\section{Theme summary}

Social assistance in crises, whether part of a social protection system or driven by humanitarian needs, provides crucial support to people affected by disaster and conflict. Accountability is a central component of delivering effective social assistance. The increasing emphasis on reinforcing social protection in fragile contexts and the Grand Bargain 'participation revolution' workstream suggest the need for a fresh look at accountability frameworks and how they play out in practice for the people they aim to serve.
Approaches to accountability are usually researched and analysed separately as part of social protection, humanitarian, or governance (citizenship) responses in fragile contexts. This brief therefore seeks to connect evidence from humanitarian and development accountability approaches to better understand the linkages and disconnects, as well as to identify opportunities for future research and learning.

This thematic brief is a shortened version of a BASIC Research Working Paper. To explore this research theme in more detail please refer to:

Seferis, L. and Harvey, P. (2022) Targeting: Accountability in Crises: Connecting Evidence from Humanitarian and Social Protection Approaches to Social Assistance, BASIC Research Working Paper 13, Brighton: Institute of Development Studies, DOI: 10.19088/BASIC.2022.013

A full list of the references cited in this brief can be found at the BASIC Research Zotero library.

Implemented by

institute of development studies

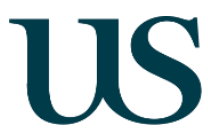

UNIVERSITY OF SUSSEX

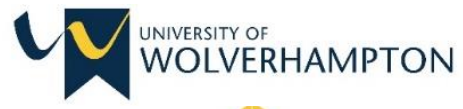

\section{CIDT}

Better Assistance in Crises (BASIC) Research (funded by UKAid) aims to inform policy and programming on how to help poor and vulnerable people cope better with crises and meet their basic needs through more effective social assistance. All costs related to BASIC Research are covered by the UK Foreign, Commonwealth and Development Office. 


\section{State of the evidence and debate}

Both social protection and humanitarian assistance have commitments to accountability but use different language and approaches. Social protection actors focus on 'social accountability', an umbrella term for mechanisms that seek to operationalise direct accountability relationships between citizens and the state using a rights-based approach (Malena et al. 2004). Humanitarian 'accountability to affected populations' (AAP) centres on direct accountability between aid agencies and aid recipients.

- Social accountability theory draws on collective action and citizen engagement, with a focus on rights-based citizen-state relationships.

- Humanitarian approaches often have blind spots around politics, governance, and rights. Humanitarian frameworks have difficulties in using citizen engagement models when people affected by crisis are not citizens or are systematically denied a voice and access to systems and services.

- Social protection and humanitarian approaches, in fact, rely on similar mechanisms for accountability. Both emphasise grievance and redress mechanisms (GRM), also called complaints and feedback mechanisms (CFM). ${ }^{1}$ Best practice underlines the importance of two-way communication rather than one-way information provision from providers to recipients - and investment in proactive engagement alongside CFM and GRM (Sabates-Wheeler et al. 2019; CDAC Network 2019; Ground Truth Solutions 2020).

- Normative commitments to accountability do not systematically translate into more effective practice. Accountability is often conflated with participation, both in humanitarian responses and social protection programming in fragile contexts (Grandvoinnet et al. 2015; Sattler interview 2021). There can be a 'misplaced technocratic emphasis' on reactive accountability mechanisms to foster participation, such as hotlines or community meetings, although these do not lead to the desired 'citizenship empowerment' (King and Hickey 2016; Sabates-Wheeler et al. 2019). Such engagement does not empower people to make their own decisions, as citizen engagement and participatory action stipulate (Sabates-Wheeler et al. 2019; Dinbabo 2003).

Table 1: Social Accountability and AAP - comparing and contrasting key components

\begin{tabular}{|c|c|c|}
\hline & Social accountability & AAP \\
\hline Duty bearer & $\begin{array}{l}\text { The state - social protection actors and others } \\
\text { in government, or de facto authorities }\end{array}$ & $\begin{array}{l}\text { Aid providers - humanitarian agencies (often } \\
\text { with an international focus) }\end{array}$ \\
\hline Rights holder & $\begin{array}{l}\text { Focus on citizens and on the rights of citizens } \\
\text { to social protection and assistance }\end{array}$ & $\begin{array}{l}\text { Focus on recipients or 'beneficiaries' of } \\
\text { humanitarian aid and is needs as opposed to } \\
\text { rights-based }\end{array}$ \\
\hline $\begin{array}{l}\text { Framing } \\
\text { principles and } \\
\text { standards }\end{array}$ & $\begin{array}{l}\text { Embedded in legislation and/or within sector or } \\
\text { programme-specific service standards and } \\
\text { charters }\end{array}$ & $\begin{array}{l}\text { Humanitarian Accountability Partnership (HAP) } \\
\text { standards - evolved into the Core } \\
\text { Humanitarian Standard }\end{array}$ \\
\hline $\begin{array}{l}\text { Language around } \\
\text { rationale and } \\
\text { objectives }\end{array}$ & $\begin{array}{l}\text { Assistance is framed as a right and states are } \\
\text { framed as the duty bearers in fulfilling peoples' } \\
\text { rights }\end{array}$ & $\begin{array}{l}\text { Assistance is framed around need and } \\
\text { vulnerability with aid agencies meeting } \\
\text { humanitarian imperatives when states are } \\
\text { overwhelmed or unwilling to act }\end{array}$ \\
\hline Role of the state & $\begin{array}{l}\text { State-centric; about the people's ability to hold } \\
\text { the state to account; and state duties to provide } \\
\text { assistance and inform people }\end{array}$ & $\begin{array}{l}\text { Focused on direct accountability between aid } \\
\text { agencies and aid recipients with the state } \\
\text { largely absent }\end{array}$ \\
\hline
\end{tabular}

${ }^{1}$ See Barca (2016) on grievance mechanisms for social protection programmes, and Bonino et al. (2014) for humanitarian feedback mechanisms. 


\begin{tabular}{|l|l|l|}
\hline Social contract & $\begin{array}{l}\text { Social accountability seen as part of a process } \\
\text { by which social protection contributes to a } \\
\text { social contract between a state and its citizens }\end{array}$ & Social contract language largely absent \\
\hline Frontline staff & Social workers, programme staff & Protection case workers \\
\hline
\end{tabular}

Sources: Barca et al. 2021; CHS 2020; Grandvoinnet et al. 2015; Seyfert et al. 2019; Sabates-Wheeler et al. 2019.

\section{Gaps in the evidence}

Social assistance accountability generally struggles to demonstrate the connection between feedback and improved programming. Rhetoric on connecting communities/recipients to decision makers is prominent in accountability policies and frameworks across humanitarian aid and social protection, but evidence of effective feedback in practice is lacking (Humanitarian Accountability Report 2020; Barbelet 2021). The power or authority delegated to frontline workers is rarely examined. Upwards accountability may disincentivise frontline workers from reporting issues to managers, or engaging in dialogue with communities, lest they raise issues that up-end the system. Some approaches go beyond rhetoric to define meaningful dialogue (see CashCap 2020), but the evidence base for these is still being built.

- Evidence on social assistance accountability rarely considers both social protection and humanitarian approaches, and the intersection between the sectors. Research centres chiefly on guidance (what agencies should do) or activities (how organisations communicate with communities). Evidence is lacking on how accountability relationships unfold in fractured societies, and how they affect people's ability to hold duty bearers to account.

- A primary under-researched area concerns the opportunities and challenges around accountability and localisation, especially related to transferring power and accountability to local actors (ODI 2021). Even less research exists on communities where social protection systems and humanitarian responses intersect.

- Systematic analysis is needed to understand different cultures of participation in protracted crises and situations of contested authority. This includes dynamics around people's 'unwillingness to complain', courtesy bias towards service providers, opportunity costs of participating, and whether people mistrust outcomes (de Wijn et al. 2018; Barca 2021). Power dynamics, inclusion and the inherent heterogeneity of communities and the state are not often reflected in the evidence, although power dynamics appear in social accountability frameworks (Grandvoinnet et al. 2015). Power is key to understanding how people may engage in social assistance programmes in a crisis, and what mechanisms or tools could yield stronger accountability outcomes.

- The disconnect between policy and practice makes it difficult to understand whether people affected by crisis can and want to actively participate, how best to engage them in social assistance, and what mechanisms or approaches best suit specific crises. 


\section{Directions for research}

Accountability is instrumental to more effective and sustainable social assistance in crises. BASIC Research will integrate research questions on accountability in Iraq, Nigeria and Somalia to address the evidence gaps on accountability at the intersection between humanitarian aid and social protection assistance.

- Accountability pathways are a 'blueprint' for how accountability is expected to function. If understood and mapped, these pathways can enhance knowledge of how accountability works in practice (and influence broader considerations of power, social contract, inclusion). Key questions in mapping these pathways include:

- What does the intersection between humanitarian AAP and social accountability look like in each context: who is accountable to whom, and how do different actors participate?

- What do people see as key issues in navigating safe access to assistance?

- Who do they rely on to resolve problems about eligibility for or receipt of assistance?

- How are humanitarian and social protection approaches to accountability for assistance linked, and to what extent are they linked to governance and protection challenges? Are there examples of where accountability mechanisms have been shared across sectors (e.g., national social protection systems taking refugees as caseloads), and what learning emerged from these examples?

- What is the relationship between social accountability and AAP versus accountability to donors: where are the tensions and what are the trade-offs for social assistance?

- BASIC Research aims to understand what 'locally accountable' means for social assistance in the identified protracted crises, specifically:

- Which factors and/or processes contribute to stronger accountability, and how?

- What are the capacities or skills needed to implement strong accountability?

- How do these elements differ or change depending on contexts, regions, and over time?

- How does civil society play a role in accountability between communities and service providers, and what are the implications for localisation?

\section{Acknowledgements and Disclaimer}

This document was developed by the Better Assistance in Crises (BASIC) Research programme. BASIC is implemented by the Institute of Development Studies (IDS), the University of Sussex and the Centre for International Development and Training, funded by UKAid from the UK government. The views expressed in this document are entirely those of the authors and do not necessarily represent views or policies of the UK governments official policies.

C) IDS copyright 2022. Copyright in the typographical arrangement and design rests with IDS.

This publication (excluding the logos) may be reproduced free of charge in any format or medium, provided that it is reproduced accurately and not used in a misleading context. The material must be acknowledged as IDS copyright with the title and source of the publication specified.

Published by IDS.

DOI: $10.19088 / B A S I C .2022 .026$ 